\title{
Procrastination and the Shifting Political Media Environment: An Experimental Study of Media Choice Affecting a Democratic Outcome
}

\author{
Morgan E. Ellithorpe, R. Lance Holbert, \& Angela L. Palmer-Wackerly
}

Morgan E. Ellithorpe is a Doctoral Student in the School of Communication at The Ohio State University.

R. Lance Holbert is an Associate Professor in the School of Communication at The Ohio State University. Angela L. Palmer-Wackerly is a Doctoral Student in the School of Communication at The Ohio State University.

Corresponding author - Morgan E. Ellithorpe, current address: Annenberg Public Policy Center, University of Pennsyl;vania, mellithorpe@asc.upenn.edu

\begin{abstract}
The shifting media environment is expected to have a variety of effects on political knowledge and behavior. An experimental study was conducted to assess the influence of media environment on news consumption, perceptions of media experience quality, and success on a political outcome. In addition, procrastination is introduced as a potentially important individual-difference variable with assessments offered for both its main effects and its ability to moderate the influence of media environment. Media environment complexity predicted lower news use and higher success on our political outcome. Procrastination's effect was on media experience perceptions and a media environment-by-procrastination interaction on this portion of the hypothesized model. These outcomes then went on to predict success on a task analogous to democratic participation.
\end{abstract}

Keywords: media environment, news consumption, political communication, procrastination

The political media environment in which we find ourselves is increasingly complex and selection based, and the trajectory indicates that even greater choice in media is likely with every election cycle (Prior, 2007). During the 2012 U.S. presidential election, voters 
wishing to seek information about the election issues and candidates had the choice between not only the major networks but also dozens of cable channels, Internet Web sites, newspapers, magazines, and social media. An important question, therefore, is what effect does this amount of media choice have on citizen participation and election outcomes? And, given the fact that this trend is likely to continue, what other variables might play a role in determining those outcomes?

The issue of increased selectivity within the media environment has captured center stage in recent discussions concerning the future of political media effects research (e.g., Bennett \& Iyengar, 2008; Holbert, Garrett, \& Gleason, 2010). Initial research on the effects of selective media exposure on democratic outcomes has focused on the audience characteristics of political ideology and party identification (e.g., Jamieson \& Cappella, 2009; Stroud, 2011). In addition, we know that the selective consumption of political media content affects some of our most basic democratic outcomes like political knowledge (Eveland, Hayes, Shah, \& Kwak, 2005; Holbert, 2005) and vote choice (e.g., Beck, Dalton, Greene, \& Huckfeldt, 2002). However, there needs to be increased focus given to additional individual differences in relation to media choice behavior, what people take away from their mass-mediated political communication experiences, and how various acts of media engagement affect a wide range of democratic outcomes. The current research effort focuses on an individual-difference variable previously overlooked in the political communication literature: procrastination (Steel, 2007).

Procrastination is "to voluntarily delay an intended course of action despite expecting to be worse off for the delay" (Steel, 2007, p. 66). It will be argued that procrastination can affect not only media choice decisions made in the context of an altering media environment but also impact individual-level perceptions of the media experiences people choose to engage in over time. For example, in the political realm, citizens may procrastinate from the act of seeking out specific types of media to learn about various candidates who are competing with one another for an elected office. The pool of primary candidates, in particular, can be large and confusing, with the supposed "frontrunner" changing rapidly. In the months leading up to the 2012 primary election, Michelle Bachmann, Herman Cain, Rick Perry, Rick Santorum, and Ron Paul were all declared potential winners at one point or another before Mitt Romney finally emerged as the Republican nominee. Keeping track of all of these candidates and their positions, as well as their ever-changing likelihood of winning at any given time, may have required more effort than some voters wanted to provide. Therefore, it is possible that some voters decided to simply put off their decision, biding their time until the choice became easier or the field of candidates was narrowed. This could be achieved in many ways, including changing the channel when the topic of the primaries comes up, or making it clear to conversation partners that a person has little interest in discussing the candidates.

\section{The Media Environment and Procrastination}

Traditional research conducted on the concept of procrastination typically focuses on 
outcomes like learning (Howell \& Watson, 2009; Wolters, 2003). However, it is often the communicative act (e.g., attention to news about primary candidates), not the actual knowledge derived from it, which is most immediately being delayed in various procrastination scenarios. In addition, the potential influence of procrastination on media behavior becomes more complex when we acknowledge that a delay in engaging one type of media (e.g., news) can be facilitated by the selection of other media (e.g., sitcoms). According to uses and gratifications theory (Katz, Blumler, \& Gurevitch, 1973), individuals select media to consume based on their current needs, one of which could be to gain information about a candidate, political issue, or event (in gratifications research, "surveillance need"; Katz et al., 1973). Previous research has shown that the seeking of news is positively related to surveillance needs (Vincent \& Basil, 1997). However, this need for information could also be in competition with other needs, such as for social connection or distraction, which would be better served by choosing to consume purely entertainment media. If the individual is procrastinating learning about political information, then the other competing needs would likely prevail, and news media would be avoided to the extent that this avoidance is possible.

Lucky for the procrastinator, but perhaps less so for society, Prior (2007) reveals that, in the postbroadcast age, an expansion in the number of media outlets and forms (e.g., cable, Web) and a larger percentage of media outlets devoted to entertainment content has led to a natural reduction in the consumption of news. Individuals who in a broadcast age (when there was a relatively small number of outlets; Chaffee \& Metzger, 2001) would have been almost forced to consume some news can now easily circumvent exposure to news altogether in the current media environment. Although a smaller proportion of the general media audience can be defined as news consumers than in the past (Prior, 2005, 2007), there has been little work devoted to isolating individual-difference variables that can moderate the likelihood of news consumption. Procrastination is one such possible moderator.

According to a meta-analysis by Steel (2007), $80 \%$ to $95 \%$ of college students procrastinate, and about $50 \%$ do so chronically. In the general population, about $20 \%$ of adults can be classified as chronic procrastinators, but it is commonly assumed that many more do so occasionally. The likelihood of procrastination tends to increase as the task at hand becomes more aversive, ambiguous, or difficult, or when the reward for task completion is small and=or temporally distant (Harris \& Sutton, 1983; Steel, 2007). Given the potential for heightened influence of procrastination under specific circumstances (e.g., aversive task, heightened ambiguity, distant rewards), this individual-difference variable may be particularly influential in political matters. Political issues can be difficult to understand, dry and boring, and ambiguous (i.e., strong opposing arguments) and learning about them can also be incredibly time consuming (Fowler \& Kam, 2006). The task of becoming an informed citizen is not an easy, sexy, or particularly entertaining proposition for many individuals (Bartels, 1996). Consider, for example, the sheer number of complex issues covered in the 2012 election, including healthcare, education, foreign policy, immigration, war and terrorism, etc. To truly understand any of these topics would require a great deal of time and effort. Politics is saddled with high task aversion and low 
rewards that are realized only with great temporal distance, and all of these characteristics increase the likelihood that people will procrastinate.

One possible explanation for political behavior in the face of all of these disincentives is that individuals may turn to simple heuristic processing and mental shortcuts to make the choice easier (e.g., Popkin, 1995). In this way, individuals can still feel informed and can make decisions without the psychological discomfort of uncertainty or the cognitive effort required to ignore an issue. However, mental shortcuts cannot be used successfully all the time. First of all, one must have at least the basic background knowledge required to create and apply the shortcut in the first place (Popkin, 1995). In our ever-changing political world, there are bound to be new candidates and new issues that the average citizen knows nothing about and cannot make any sort of judgment, even a heuristic one, without learning at least a little bit about the topic.

Popkin (1995) outlines the five major mental shortcuts that people use: opinions of trusted others, political party, demographic traits of candidates, campaign behavior, and candidate sincerity. These things may help to make a quick decision, but one could argue that the only way that voters could have even that small amount of information (such as how the candidate behaves on the campaign trail or what trusted news organizations say about them) would be to consume some level of news information regarding the candidate. But what if the individual is overwhelmed by the dozens of primary candidates or the complexity of an issue like nuclear nonproliferation and so chooses to completely avoid information? On what basis would he or she be able to form a heuristic that can be successfully applied? It is possible that it is at this point, when the task is so onerous as to be overwhelming, that procrastination may take over and mental shortcuts lose their power (whether through not being formed, or through being applied badly). And therefore, this is when alternative needs that can be met with entertainment media will be preferred over the need for information that news can gratify.

\section{A Hypothesized Process Model}

A four-stage process model serves as a foundation for the current study (see Figure 1). Building off of the work of Prior (2007), it is argued that as more nontraditional news media choices, relative to a stable number of news choices, are made available to audience members there will be a reduction in news consumption (H1). In addition, there is

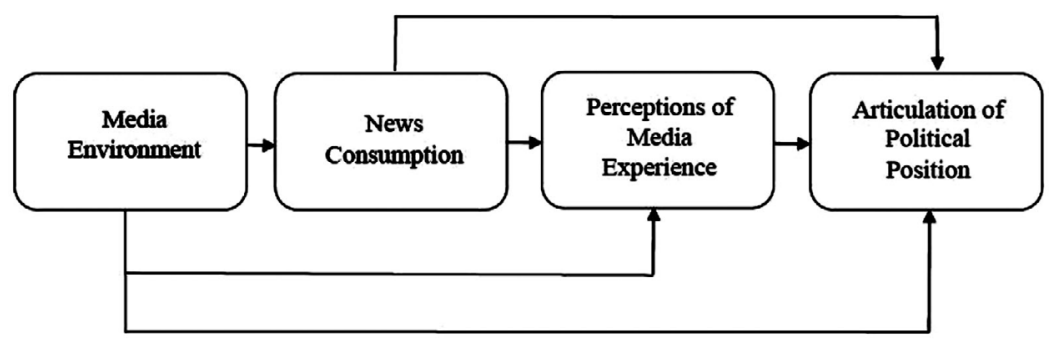

Figure 1. Baseline Hypothesized Model of Media Environment Influence. 
a long tradition of argument that citizens are assigned the task of becoming informed in order for a democracy to function well (see Milner, 2002). One source of information related to politics and public affairs is news, and news consumption has been shown to play an integral role in the creation of a more informed citizenry (see McCombs, Holbert, Kiousis, \& Wanta, 2011). When assigned the task of becoming an informed citizen, individuals will seek to gratify specific needs through media consumption (Rubin, 2009). In the case of a surveillance motivation, news consumption should not only impart information but should also give citizens the perception that they actually have learned, gratifying the need. In short, greater levels of news consumption should generate more positive perceptions of feeling one's media experiences were fruitful in terms of serving a surveillance function (H2).

The criterion variable focused on in this study is the ability to articulate a wellreasoned and quality argument that reflects a given political stance. There has been much research in the past looking at how the complexity of the media environment might affect how people engage with media and use it to create democratic outcomes (e.g., Prior, 2007; Stroud, 2008,2011 ). Does the offering of more information in the form of additional media outlets produce a positive effect, or does increased choice result in a negative main effect on our outcome variable (RQ1)? Along the same lines as amount of choice, the types of choices offered in a given media environment should also affect what people choose to consume (Stroud, 2008). Specifically, we want to know whether alterations to the media environment in the form of an increase in the ratio of entertainment to traditional news material impacts perceptions of what people take away from their media experiences. Does increased choice in type of media serve to enhance or diminish a sense of task-related gratification derived from media consumption (RQ2)?

Normatively, the consumption of more news material that is specific to the assigned democratic task should aid in the production of more positive outcomes. Previous research is fairly clear about the effects of news consumption on political learning and knowledge. In general, greater news consumption is related to greater levels of knowledge about politics (Eveland et al., 2005), and this should translate over to greater ability to articulate a well-informed political position (H3). In addition, perceptions of learning from news should also have a positive main effect on our democratic outcome (H4). Perceived learning can be viewed as a construct as the perceptions of how much one has learned from their media experience. Previous research has shown that perceived learning increases self-efficacy to engage in a knowledge-related task (Schunk, 1985, 1991), and self-efficacy has been shown in turn to positively affect task performance (Liem, Lau, \& Nie, 2008; Multon, Brown, \& Lent, 1991).

\section{Introduction of procrastination to hypothesized process model}

News consumption. If individuals are assigned a task to learn about a particular public policy issue with the intention of being able to offer others a well-reasoned argument as to where they stand on the issue, then those who rank higher in procrastination will be less 
likely to engage in those media activities that may be seen as most beneficial to achieving the stated goal. In the context of the current study, the most beneficial media outlet is traditional news consumption. ${ }^{1}$ Therefore, procrastination should be a negative predictor of news consumption (H5). Individuals who rate higher in procrastination will consume less of the media material deemed most beneficial for the task at hand.

Perceptions of media experience. Procrastinators are usually less satisfied with their performances and experiences; when attempting a task, they are often preoccupied with indecision, anxiety, and self-doubt and blame their inadequate performance on external factors such as time constraints or task difficulty (Chu \& Choi, 2005; Ferrari, 2001). These feelings are wide-spread across a range of activities, and we argue this effect should seep over to include perceptions of gratifications from media experiences, such that higher levels of procrastination will result in news media experiences being less gratifying (H6).

Articulation of political position. Procrastinators put off tasks to the point where it is detrimental to their goals, they feel a sense of learned helplessness, and their procrastination leads to negative outcomes in relation to the quality of their work and their mental wellbeing (Choi \& Moran, 2009; Chu \& Choi, 2005; Steel, 2007). There is reason to believe, based on previous research on the negative outcomes of procrastination, that people who are higher in procrastination will not perform as well on the outcome task as people who rate lower on this individual-difference variable (H7).

Procrastination as moderator of media environment effects. There is much research devoted to how the individual difference variable of ideology interacts with media selectivity (Iyengar \& Hahn, 2009). Basically, the expansion of the political media environment has produced different effects for Democrats, Republicans, and Independents. The general question we wish to put forward in this work is whether the individual-difference variable of procrastination may serve as an additional moderator of the democratic effects of alterations in the media environment (RQ3). Do the impacts of changes in the media environment on democratic outcomes vary for those individuals who retain different levels of procrastination? These questions need to be addressed in order to better understand how changes in the media environment can produce differential effects on citizens.

\section{Method}

\section{Design}

Participants were randomly placed into one of three experimental between-subjects conditions representing different media environments: low choice (TV News only), moderate choice (TV News or infotainment), and high choice (TV News, infotainment, or pure TV entertainment programming). Subjects were asked to choose on four sequential occasions 
(within a single experimental session) one video clip to watch from an array of choices depending upon their assigned condition.

\section{Participants}

There were 116 participants, undergraduates at a large Midwestern university, who were granted extra credit for their participation. The median age was 20, and 69 (61\%) were female.

\section{Procedure}

Participants gave informed consent upon arriving at the laboratory and were led to a private room containing a desk and computer. Participants first filled out a questionnaire, which included variables such as trait procrastination, political knowledge, self-efficacy, and need for cognition, among other questions. Order of questionnaire scales and items within scales were randomized. After the questionnaire, participants were told that they would write a persuasive essay at the end of the experiment, answering a prompt to which they will be assigned, and that the top five essays would win 50 dollars at the end of the study (averaging a month later). There were two reasons for the prize offering: First, it was meant as an incentive for undergraduate students to take the task more seriously than they might have otherwise; and second, it was included based on prior research that procrastination is likely to occur when potential benefits to completing the task will occur in the future rather than directly upon task completion (Steel, 2007). This feature of the study is also supported by research showing that people tend to discount the value of distant rewards (e.g., Critchfield \& Kollins, 2001).

Participants were randomly assigned one of three possible prompts, which were: "Should the U.S. be more aggressive in its dealings with Iran's nuclear potential?"; "Should the U.S. impose stronger regulations on companies that contribute to environmental degradation?"; and "Should the U.S. defense budget be cut for Fiscal Year 2012?" These prompts were designed to be topics that would not be salient or inherently interesting to the average undergraduate. Multiple prompts were chosen in order to avoid case-category confounds and with the hope that if an external event should occur pertaining to one of these topics (e.g., an oil spill) the other two could still be operationalized as topics that undergraduates would not be overly familiar with.

It was then explained that before writing the essay, participants were being given an opportunity to learn about their topic by watching up to four video clips. In condition one, subjects only had the choice between watching news (CNN) or sitting quietly at their desk (those who chose this option reported doing homework, e-mailing, or texting). ${ }^{2}$ In condition two, they had the added choice of watching infotainment (The Daily Show with Jon Stewart). And in condition three, they had all of the above choices as well as clips from various pure entertainment television shows. 
Participants then went through four sequential rounds of video choices with only a few questions evaluating the clip they just watched before making their next choice. It took most participants about 20 minutes to watch and evaluate all four clips. All participants remained in the low-, moderate-, or high-choice media environment in which they were initially placed for the entire experiment. Participants had the ability to choose one video clip in each round, and were given the clip titles to facilitate their choices. For all participants in all conditions, the same four CNN clips were offered at each time point for each of the three topics (12 clips total). In the second (moderate choice) and third (high choice) conditions, the four topical The Daily Show clips (12 total) were included. Condition three (high choice) had the added choice between four entertainment shows (16 entertainment clips total).

Therefore, if an individual wished to watch CNN content on the topic of their essay for the duration of the experiment, he or she would have four different clips to choose from across the four rounds. He or she would therefore see every CNN clip available for his or her topic once the last round had been completed. After each round, subjects evaluated the clip they just watched before moving on to the next clip. Participants were asked to write the essay upon finishing the fourth clip round and were allowed to write for as long as they liked. The experimenter was instructed to stop participants after more than 25 minutes of writing, but no participants exceeded this time limit. After the essay, participants answered demographic questions and had the opportunity to enter an e-mail address if they wished to have their essay entered into the prize contest.

\section{Materials}

Depending on condition, participants were given the option of choosing to watch CNN; CNN or The Daily Show; or CNN, The Daily Show, or one of four entertainment clips (House, How I Met Your Mother, Saturday Night Live, or The Dog Whisperer). The clips from CNN and The Daily Show pertained to the essay topics; the clips from the entertainment shows were unrelated to the topics. The clips from CNN and The Daily Show were selected based on the following criteria: They had to cover the topic for the duration of the clip, the clip must be between 4 and 7 minutes in duration, and they should be recent (within the past 5 years, with the exception of one clip from The Daily Show about the defense budget that was from 2004). For the entertainment clips, we chose the four shows based on the criteria that they each were nominated for an Emmy Award within the last 5 years for one of the four main Emmy categories: Comedy (How I Met Your Mother), Drama (House), Variety/Music (Saturday Night Live), and Reality (The Dog Whisperer). From those lists, we chose shows that were relatively long-running (i.e., more than five seasons) in order to ensure that the participants will have heard of them and therefore would not likely need a description of the show to make their choice. In order to choose the clips, we used episodes from the first seasons of How I Met Your Mother, House, and The Dog Whisperer in order to remain consistent. We decided to use some of the more famous clips from Saturday Night Live, rather than older ones specifically, in order to increase its relevance to 
undergraduates. All entertainment clips were edited to be between 4 and 7 minutes to be consistent with the clips from CNN and The Daily Show.

\section{Essay Score Calculations}

Each essay topic was meant to reflect a different political realm: foreign policy (Iran), domestic social policy (environment), and domestic economic policy (defense budget). Multiple prompts were chosen in order to avoid case-category confounds. The assumption of a lack of familiarity is supported by the fact that participants did not perform very well on nine knowledge questions (three for each topic) that were included in the questionnaire $(M=1.91, S D=1.39, \min =0, \max =5)$. The essay was chosen as an example of an effortful political situation analogous to something participants might encounter in real life. The task of recalling facts and arguments as well as articulating a persuasive opinion is something likely to be encountered in situations like holding political conversations with friends and family, evaluating claims of politicians and pundits, and in deciding who to vote for in an election.

All essays were graded by two independent coders who were blind to the purpose of the study. These coders were graduate students who were selected for their familiarity with grading persuasive essays using a similar rubric to that used for the coding scheme. They were trained using 10 randomly selected essays in which they went through the rubric together with the experimenter, after which they coded the remaining essays separately. The coders assigned a score between 0 and 5 for the following six essay aspects: organization, grammar and style, focus, depth of thought, detail/use of facts, and argument quality. They were instructed to disregard the side of the argument that participants supported but instead focus on the quality of the arguments and any factual information that the participants included. Coders were given a list of facts that were included in the clips from CNN and The Daily Show, as well as others that could potentially come up in the essays. However, outside facts were not highly expected given participants' general lack of familiarity with the essay topics. The aspects of organization, grammar, and focus were meant to operationalize the amount of effort that participants put into the essay, while argument quality, depth of thought, and use of facts were meant to encompass topical knowledge and learning. The scores for the six aspects were then summed to create a score for each essay from each coder, and the summed scores for the two coders form a reliable two-item index (Cronbach's $\alpha=.84){ }^{3}$ The descriptive statistics for our criterion variable are as follows: $M=13.55$, $S D=6.13, S k=-0.66, K=-0.17, \min =0.00, \max =25.25$.

\section{Measures}

All scales in this study were measured on a scale from 1 to 11 unless otherwise specified. 


\section{Procrastination}

Procrastination as a trait variable was measured using the Aitken Procrastination Inventory (API; Ferrari, Johnson, \& McCown, 1995). This scale assesses how often participants engage in procrastination behaviors and includes items such as "I delay starting things until the last minute" and "even when I know a job needs to be done, I never start it right away." The API (19 items, $M=5.09$, SD = 1.51) had solid reliability (Cronbach's $\alpha=.87$ ). The API was masked by mixing it randomly with items from the Need for Cognition scale in order to decrease potential suspicions about the nature of the study.

\section{Media choice}

In order to create a measure of news media consumption across the four choice rounds, a choice of news was coded as 1 and any other choice was coded as 0 . This score for the four rounds was then summed to create a 0 -to- 4 scale, with 0 representing choosing to watch no news during the entire experiment and 4 indicating that the participant chose news in all four rounds $(M=2.27, S D=1.27)$.

\section{Clip evaluation}

In this context, presumably the gratifications that participants would have to seek in order to perform well on the essay are those that are related to perceptions of learning and self-efficacy to complete the task. An index of evaluations from each of the four rounds was calculated using the items "The clip I just watched helped me prepare for the essay" and "I learned a lot in the clip I just watched" $(M=6.52, S D=2.02$, Cronbach's $\alpha=.83)$.

\section{Task aversion}

Aversiveness of the task at hand is an important predictor of procrastination (Steel, 2007), but to our knowledge there was no official scale of task aversion available at the time of data collection. Therefore, we used the information about task aversion from Harris and Sutton (1983) and Steel to construct questions of our own. The scale included five statements, which were "Preparing for this essay will be difficult," "Preparing for the essay will be interesting" (reverse scored), "Preparing for the essay will be challenging," "The task I will have to do to prepare for the essay is ambiguous," and "The deadline for finishing my preparations for the essay is too close" $(M=6.41, S D=2.17$, Cronbach's $\alpha=.71)$.

\section{Issue topic knowledge}

Participants' pre-experiment knowledge about the issues covered in the study was assessed using three factual multiple-choice questions on each topic (total of nine), which were designed to be difficult in order to ensure variance. Order of questions and answer choices was randomized. Participants were also given the option of "Don't Know." The answers to all questions were taken from official U.N. and U.S. government documents 
and Web sites whenever possible and otherwise were from credible news sources. The number of correct responses ranged from zero to five $(M=1.91, S D=1.39)$.

\section{Internal political efficacy}

Internal political efficacy (Morrell, 2003) was used as a politics-specific form of self-efficacy, which is often found to be related to procrastination behaviors (Steel, 2007). Conceptually, putting internal political efficacy together with political knowledge was considered a measure of previous participation and interest. The scale is four items, an example of which is "I think that I am as well-informed about politics and government as most people." The Internal Political Efficacy scale $(M=4.96, S D=2.31)$ had good reliability (Cronbach's $\alpha=.86$ ).

\section{Analyses}

A single structural equation model (maximum likelihood estimation) was tested. The only additions beyond that which has been hypothesized are the three additional exogenous control variables (i.e., task aversion, issue topic knowledge, internal political efficacy), which were included due to their potential relationship with procrastination based on previous research (e.g., Steel, 2007). They were allowed to establish direct relationships with the criterion variable, essay score and were covaried with procrastination. The condition variable of media-environment complexity was treated as an ordinal-level variable based on the conceptual order from least complex to most complex. It is important to note the potential impact this could have on statistical assumptions, but it was the way we determined to be most true to the conceptual aspects of the data. The model is assessed for fit using the Confirmatory Fit Index (CFI) and the Root Mean Squared Error of Approximation (RMSEA) with both being defined as solid assessments of model fit (see Holbert \& Stephenson, 2008).

\section{Results}

\section{Model Fit}

The hypothesized model fit the data well (see Figure 2): CFI $=.989$; RMSEA $=.028(90 \%$ CI, .00-.10). For model comparison purposes, the chi-squared distributed test statistic is $(d f=12)=13.09, p>.36$. The model accounts for $41 \%$ of the variance in news consumption, $20 \%$ of the variance in media clip evaluation, and $21 \%$ of the variance in essay score.

\section{Media Environment}

There are three paths of influence from the manipulated media environment condition to the criterion essay score variable. First, there is a statistically significant, positive main 


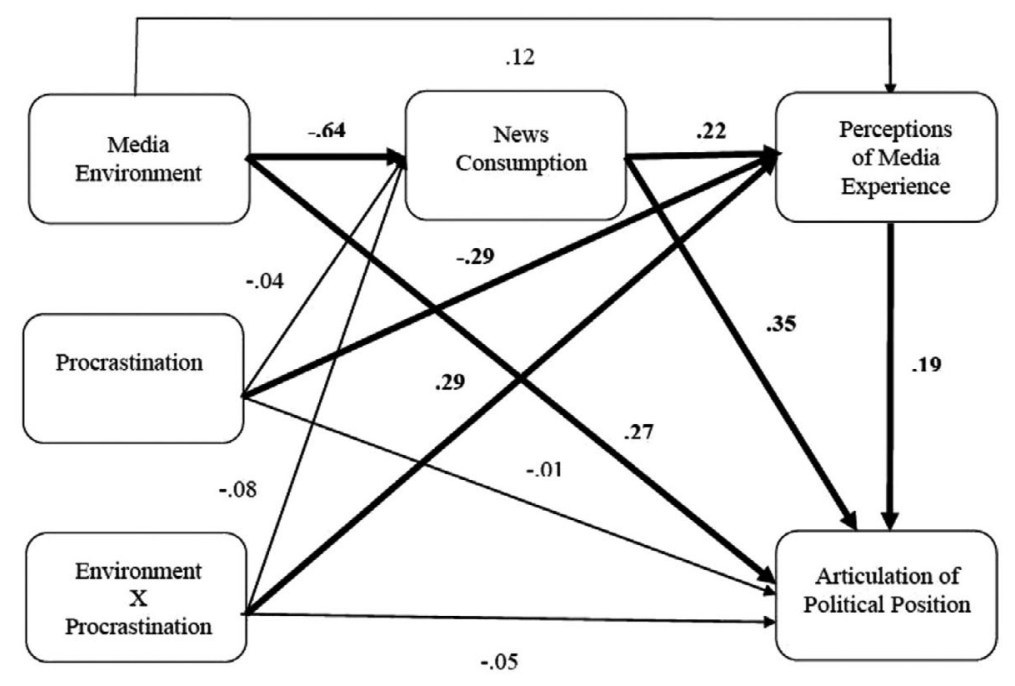

Figure 2. Media Environment and Procrastination Model Results. ${ }^{4}$

effect of condition on essay score $(\gamma=.27, p<.05)$. Individuals offered a wider range of media content performed better on the democratic outcome. However, there was a strong, negative indirect effect of condition on essay score through news consumption (standardized specific indirect effect $=-.22$ ). The experimental condition had a sizeable main effect on news consumption $(\gamma=-.64, p<.001)$. Individuals consumed less news as the media environment increased in complexity, and this is problematic in that news consumption had a positive main effect on essay score $(\beta=.35, p<.001)$. The indirect effect of media environment on this study's criterion variable runs directly counter to the main effect of media environment with the former nearly cancelling out the latter.

The final indirect path of media environment influence on essay score reflects the basic three stage model offered in the hypothesized model. As already noted, media environment has a large, negative effect on news consumption, but news consumption leads directly to a more positive overall media experience in terms of clip evaluation $(\beta=.22$, $p<.05)$. In turn, clip evaluation has a small, but positive effect on essay score $(\beta=.19$, $p<.05)$. This series of paths produces an additional specific indirect effect that runs counter to the positive main effect of media environment on essay score (standardized specific indirect effect $=-.03$ ).

\section{Procrastination}

The influence of procrastination on the endogenous portion of the model resides with its main effect of clip evaluation $(\gamma=-.29, p<.001)$. As outlined above, those who rate higher in procrastination generally rate their experiences in all facets of life as slightly poorer than those individuals who retain relatively lower levels of this individual-difference 
variable. Procrastination was not found to have a main effect on either news consumption $(\gamma=-.04)$ or essay score $(\gamma=-.01)$. The only effect of procrastination on this study's criterion variable is indirect through its influence on clip evaluation (standardized specific indirect effect $=-.06$ ).

\section{Environment-by-procrastination}

The only statistically significant effect of the media environment-by-procrastination interaction term can be found with media clip evaluation as well $(\gamma=.29, p<.001)$. In general, high procrastinators rated their media experiences worse than their low-procrastination peers, but this relatively negative evaluation was weakened when the media experiences were evaluated in a high-choice media environment. High procrastinators who are offered little choice viewed their media experiences in a particularly negative light.

\section{Summary}

The influence of media environment on the endogenous portion of the model can be fixated on level of news consumption and the criterion variable of essay score. The influence of procrastination is on individual-level perceptions of the quality of one's media experience. In addition, media environment serves to qualify the main effect of procrastination on clip evaluation, with high procrastinators feeling better about their news experience when interacting with media environments that afford more choice.

\section{Discussion}

The present study indicates an indirect but important role for procrastination in political processes. In the case of political learning from media, procrastination negatively affects how much people feel they got out of a news experience, and this produces an indirect effect that decreases their ability to perform well on a political task. Political learning is an area, which is ripe for study of procrastination, especially given the task aversion many people experience with learning about politics and the drawn-out nature of elections (Bartels, 1996; Fowler \& Kam, 2006). However, these results are not just applicable to political learning; there is benefit for understanding procrastination in all areas of the political science and communication fields. For example, procrastinating actually going to the polls to vote until the evening of election day can often be met with long lines, frustration, and a negative experience. Indeed, in the 2012 election, voters waited in line on Election Day for up to 8 hours in some states, with polling places having to stay open later than planned, and people remained in line in Florida even after President Obama was declared the national winner (Klas, 2013). Perhaps this negativity, caused in part by putting off voting until the last minute, could lead to a lower likelihood of voting at all in the next election cycle. Future research should look to alternative contexts such as this in applying procrastination processes. 
The interaction between media environment and procrastination for media clip evaluation identified in the current study is worthy of additional exploration. As is found in many other facets of life, individuals who rate higher in procrastination perceive their life experiences more negatively. This is true for media engagement as well. While this effect may seem inconsequential in comparison to the ability to predict when people will choose to consume news or entertainment, it is in fact an important facet of predicting behavior. We know that variables such as self-efficacy and perceived behavioral control are incredibly important for predicting behavior (e.g., see Theory of Planned Behavior; Ajzen, 1991). If procrastination makes people feel more negative about their preparatory experiences before they act, as well as more negative about their ability and preparedness to act, then they are less likely to engage in quality action. This is the role that procrastination seems to play in the link between media selection and political behavior.

However, it is important to note that this relationship between procrastination and evaluation of the media experience is moderated by the media choice environment, such that the negative relationship is less so when those higher in procrastination are placed in a media environment that offers them some degree of choice. Alternations to the media environment had no main effect on individual-level perceptions of media experiences in this experiment, but the higher choice environments did allow for those high in procrastination to walk away from this activity feeling better about their media choices aiding them in completing the task at hand. Alternatively, this finding can be interpreted as a low-complexity media environment making procrastinators feel trapped, which makes them subsequently feel lower efficacy for completing a related task. If not allowed to procrastinate when they wish to, procrastinators may lash out and refuse to allow their media experiences to help them. This has important implications for any assumptions that more news exposure, regardless of how it is received, is always better. In the case of procrastinators, at least, forced exposure to news doesn't help them gain efficacy and/or perceived knowledge but instead makes them feel less efficacious and perform worse on the task at hand. Future research on other potentially important individual-difference variables that could be involved in the relationship between news consumption, media environment, and perceived efficacy and knowledge is necessary.

When looking at overall media environment effects, this study found that media environment has a substantial negative effect on news consumption, supporting and expanding upon previous survey-based research (Prior, 2005, 2007). In addition, an increase in the number of media outlets produced a positive main effect on our essay outcome. Given this finding, it could appear that more media choice can offer democratic advantages. However, this positive main effect is almost completely negated by the fact that the offering of more media options leads to less news consumption, and news use was found to be a strong and positive predictor of offering a quality argument. In short, more media information can be a democratic good, but any benefits afforded from increased choice are lost if citizens do not choose their media wisely. This outcome in particular applies greatly to issues of selective exposure in the current complex media environment. It appears that what media people select to engage with certainly does affect the quality of their democratic outcomes as measured by our essay task, which is consistent 
with previous research on exposure to news and political participation (e.g., de Vreese \& Boomgaarden, 2006).

\section{Limitations and Future Research}

Although several precautions were taken to maximize the ecological validity of this study, all experiments taking place in a laboratory setting suffer from some set of limitations. For example, the task of writing an essay with the chance of winning money is meant to be analogous to successful conversation or voting on an issue in an election. Although these tasks are not the same, we do believe we were able to get as close as possible to a scenario in which an individual would be expected to be knowledgeable about a topic and in which the potential reward for this knowledge was small and=or temporally distant. Another aspect of the experimental setting is the small window of time in which participants had to learn about the topic. Outside of the laboratory, many activities that are procrastinated are pushed back precisely because the due date is temporally distant. We suspect that this short temporal nature of the experiment could be at least in part an explanation for our lack of findings for procrastination predicting actual media choice. Short of bringing participants into the lab on four separate occasions to make media choices as a way to increase the amount of time before the essay task, it would be very difficult to change this aspect of the study. And this type of approach would bring in many different threats to internal validity, such as what participants did during the intervening time between sessions. A final aspect of the experimental method used in this study is that subjects had the right to choose not to consume any media at any one time point or altogether (see Note 2). The field is still working through how best to adopt experimental designs that better reflect the political media realities faced by the citizenry (e.g., Iyengar, 2011). As we continue to refine our experimental designs (e.g., move beyond forced exposure tests), we need to think about choice on multiple levels. One level of choice is a citizen deciding to consume one media outlet versus another media outlet. However, this decision is made in various real-world scenarios only after an earlier decision was made to engage media in the first place. Various media outlets not only compete with one another for people's attention but also with a host of nonmedia activities, which could just as easily produce similar gratifications obtained (e.g., talking with someone about politics rather than seeking news).

\section{Conclusion}

The results of this study suggest one potential role for procrastination in the relationship between selective exposure of media and political outcomes. Specifically, procrastination affects the political learning and decision-making process in an indirect way by affecting how satisfied people are with their media choices, which then in turn changes their likelihood of engaging in successful political behavior. What this suggests is that people who put off learning about the huge pool of primary candidates in the 2012 election 
should have felt less prepared to vote than did those who did not procrastinate, and this lack of preparedness could have led them to make a decision they later regretted or to decide not to vote at all. These negative outcomes could have repercussions for not only this past election but also for the next time these individuals are faced with a political decision. This experiment has also added to our knowledge of selective exposure to news, infotainment, and entertainment as part of our complex media environment. While there are many complex processes occurring during elections to determine political outcomes for citizens, the present study offers procrastination and media choice as one possibly important arena to which we should pay greater attention.

\section{Notes}

1 News consumption has been shown to have the most direct effect on political knowledge and engagement (see Eveland, 2001). In addition, even college students have been shown to retain a clear perceptual differentiation in the political gratifications associated between traditional television news and satire news (see Holbert, Lambe, Dudo, \& Carlton, 2007), with traditional television news ranked far higher than satire news.

2 The following is the breakdown of the number of individuals who chose to engage in a nonmedia activity at the four time points: Time $1, n=3$; Time $2, n=7$; Time 3, $n=10$; Time 4, $n=12$. A sizeable number of the Time $3(n=8)$ and Time $4(n=8)$ nonmedia choice respondents were assigned to the low media choice condition.

3 A more traditional estimate of intercoder reliability (i.e., Krippendorf's $\alpha$ ) was also calculated. The Krippendorf's $\alpha$ for two coders was .70, meeting the agreed upon threshold for data interpretation (Krippendorf, 2004).

4 Of the three additional exogenous variables only Task Aversion was found to have a statistically significant main effect $(\gamma=-.23, p<.01)$.

\section{References}

Ajzen, I. (1991). The theory of planned behavior. Organizational Behavior and Human Decision Processes, 50, 179-211.

Bartels, L. M. (1996). Uninformed votes: Information effects in presidential elections. American Journal of Political Science, 40(1), 194-130. doi: 10.2307/2111700

Beck, P. A., Dalton, R. J., Greene, S., \& Huckfeldt, R. (2002). The social calculus of voting: Interpersonal, media, and organizational influences on presidential choices. American Political Science Review, 96(1), 57-73. doi: 10.1017/S0003055402004239

Bennett, W. L., \& Iyengar, S. (2008). A new era of minimal effects?: The changing foundations of political communication. Journal of Communication, 58, 707-731. doi: 10.1111/j.1460- 2466.2008.00410.x

Chaffee, S. H., \& Metzger, M. J. (2001). The end of mass communication? Mass Communication and Society, 4(4), 365-379. doi: 10.1207/S15327825MCS0404_3

Choi, J. N., \& Moran, S. V. (2009). Why not procrastinate?: Development and validation of a new active procrastination scale. The Journal of Social Psychology, 149(2), 195-211. 
Chu, A. H. C., \& Choi, J. N. (2005). Rethinking procrastination: Positive effects of "active" procrastination behavior on attitudes and performance. The Journal of Social Psychology, 145(3), 245-264. doi: 10.3200/SOCP.149.2.195-212

Critchfield, T. S., \& Kollins, S. H. (2001). Temporal discounting: Basic research and the analysis of socially important behavior. Journal of Applied Behavior Analysis, 34, 101-122. doi: 10.1901/ jaba.2001.34-101

de Vreese, C. H., \& Boomgaarden, H. (2006). News, political knowledge, and participation: The differential effects of news media exposure on political knowledge and participation. Acta Politica, 41, 317-341. doi: 10.1057/palgrave.ap.5500164

Eveland, W. P. (2001). The cognitive mediation model of learning from the news: Evidence from non-election, off-year election, and presidential election contexts. Communication Research, 28, 571-601. doi: 10.1177/009365001028005001

Eveland, W. P., Hayes, A. F., Shah, D. V., \& Kwak, N. (2005). Understanding the relationship between communication and political knowledge: A model comparison approach using panel data. Political Communication, 22, 423-446. doi: 10.1080/10584600500311345

Ferrari, J. R. (2001). Procrastination as self-regulation failure of performance: Effects of cognitive load, self-awareness, and time limits on "working best under pressure". European Journal of Personality, 15(5), 391-406. doi: 10.1002/per.413.abs

Ferrari, J. R., Johnson, J. L., \& McCown, W. G. (1995). Procrastination and task avoidance: Theory, research, and treatment. New York, NY: Plenum Press.

Fowler, J. H., \& Kam, C. D. (2006). Patience as a political virtue: Delayed gratification and turnout. Political Behavior, 28, 113-128. doi: 10.1007/s11109-006-9004-7

Harris, N. N., \& Sutton, R. I. (1983). Task procrastination in organizations: A framework for research. Human Relations, 36(11), 987-996. doi: 10.1177/001872678303601102

Holbert, R. L. (2005). Intramedia mediation: The cumulative and complementary effects of news media use. Political Communication, 22(4), 447-461. doi: 10.1080/10584600500311378

Holbert, R. L., Garrett, R. K., \& Gleason, L. S. (2010). A new era of minimal effects?: A response to Bennett and Iyengar. Journal of Communication, 60(1), 15-34. doi: 10.1111/j.1460-2466- 2009-01470.x

Holbert, R. L., Lambe, J. L., Dudo, A. D., \& Carlton, K. A. (2007). Primacy effects of The Daily Show and national TV news viewing: Young viewers, political gratifications, and internal political self-efficacy. Journal of Broadcasting \& Electronic Media, 51, 20-38. doi: 10.1080/ 08838150701308002

Holbert, R. L., \& Stephenson, M. T. (2008). Commentary on the uses and misuses of structural equation modeling in communication research. In A. F. Hayes, M. D. Slater, \& L. B. Snyder (Eds.), The Sage handbook of advanced data analysis methods for communication research (pp. 185-218). Thousand Oaks, CA: Sage.

Howell, A. J., \& Watson, D. C. (2009). Procrastination: Associations with achievement goal orientation and learning strategies. Personality and Individual Differences, 43, 167-178. doi: 10.1016/j. paid.2006.11.017

Iyengar, S. (2011). Experimental designs for political communication research: Using new technology and online participant pools to overcome the problem of generalizability. In E. P. Bucy \& R. L. Holbert (Eds.), The sourcebook for political communication research: Methods, measures, and analytical techniques (pp. 129-148). New York, NY: Routledge.

Iyengar, S., \& Hahn, K. S. (2009). Red media, blue media: Evidence of ideological selectivity in media use. Journal of Communication, 59, 19-39. doi: 10.1111/j.1460-2466-2008-01402.x 
Jamieson, K. H., \& Cappella, J. N. (2009). Echo chamber: Rush Limbaugh and the conservative media establishment. New York, NY: Oxford University Press.

Katz, E., Blumler, J. G., \& Gurevitch, M. (1973). Uses and gratifications research. The Public Opinion Quarterly, 37(4), 509-523. doi: 10.1086/268109

Klas, M. E. (2013, May 21). Gov. Rick Scott signs elections bill to fix long voter lines. The Miami Herald. Retrieved from http://miamiherald.com

Krippendorf, K. (2004). Content analysis: An introduction to its methodology (2nd ed.). Thousand Oaks, CA: Sage.

Liem, A. D., Lau, S., \& Nie, Y. (2008). The role of self-efficacy, task value, and achievement goals in predicting learning strategies, task disengagement, peer relationship, and achievement outcome. Contemporary Educational Psychology, 33, 486-512. doi: 10.1016/j.cedpsych.2007.08.001

McCombs, M. E., Holbert, R. L., Kiousis, S., \& Wanta, W. (2011). The news and public opinion: Media effects on civic life. London, United Kingdom: Polity Press.

Milner, H. (2002). Civic literacy: How informed citizens make democracy work. Hanover, NH: University Press of New England.

Morrell, M. E. (2003). Survey and experimental evidence for a reliable and valid measure of internal political efficacy. Public Opinion Quarterly, 67, 589-602. doi: 10.1086/378965

Multon, K. D., Brown, S. D., \& Lent, R. W. (1991). Relation of self-efficacy beliefs to academic outcomes: A meta-analytic investigation. Journal of Counseling Psychology, 38, 30-38. doi: 10.1037/0022-0167.38.1.30

Popkin, S. L. (1995). Information shortcuts and the reasoning voter. In B. Grofman (Ed.), Information, participation, and choice: An economic theory of democracy in perspective. Ann Arbor, MI: University of Michigan Press.

Prior, M. (2005). News vs. entertainment: How increasing media choice widens gaps in political knowledge and turnout. American Journal of Political Science, 49(3), 577-592. doi: 10.1111/ j.1540-5907.2005.00143.x

Prior, M. (2007). Post-broadcast democracy: How media choice increases inequality in political involvement and polarizes elections. New York, NY: Cambridge University Press.

Rubin, A. M. (2009). Uses-and-gratifications perspective on media effects. In J. Bryan \& M. B. Oliver (Eds.), Media Effects: Advances in theory and research (pp. 165-184). New York, NY: Routledge.

Schunk, D. H. (1985). Self-efficacy and classroom learning. Psychology in the Schools, 22(2), 208-223. doi: 10.1002/1520-6807(198504)22:2 < 208::AID-PITS2310220215>3.0.CO;2-7

Schunk, D. H. (1991). Self-efficacy and academic motivation. Educational Psychologist, 26, 207-231. doi: 10.1080/00461520.1991.9653133

Steel, P. (2007). The nature of procrastination: A meta-analytic and theoretical review of quintessential self-regulatory failure. Psychological Bulletin, 133(1), 65-94. doi: 10.1037/ 0033-2909.133.1.65

Stroud, N. J. (2008). Media use and political predispositions: Revisiting the concept of selective exposure. Political Behavior, 30, 341-366. doi: 10.1007/s11109-007-9050-9

Stroud, N. J. (2011). Niche news: The politics of news choice. Oxford, United Kingdom: Oxford University Press.

Vincent, R. C., \& Basil, M. D. (1997). College students' news gratifications, media use, and current events knowledge. Journal of Broadcasting and Electronic Media, 41, 380-392. doi: 10.1080/ 08838159709364414

Wolters, C. A. (2003). Understanding procrastination from a self-regulated learning perspective. Journal of Educational Psychology, 95(1), 179-187. doi: 10.1037/0022-0663.95.1.179 